\title{
Unil
}

UNIL | Université de Lausanne

Unicentre

$\mathrm{CH}-1015$ Lausanne

http://serval.unil.ch

Year : 2012

\section{Helicopter rescue involving the winching of a physician.}

\author{
CORNICHE Jocelyn
}

CORNICHE Jocelyn, 2012, Helicopter rescue involving the winching of a physician.

Originally published at : Thesis, University of Lausanne

Posted at the University of Lausanne Open Archive.

http://serval.unil.ch

\section{Droits d'auteur}

L'Université de Lausanne attire expressément l'attention des utilisateurs sur le fait que tous les documents publiés dans l'Archive SERVAL sont protégés par le droit d'auteur, conformément à la loi fédérale sur le droit d'auteur et les droits voisins (LDA). A ce titre, il est indispensable d'obtenir le consentement préalable de l'auteur et/ou de l'éditeur avant toute utilisation d'une oeuvre ou d'une partie d'une oeuvre ne relevant pas d'une utilisation à des fins personnelles au sens de la LDA (art. 19, al. 1 lettre a). A défaut, tout contrevenant s'expose aux sanctions prévues par cette loi. Nous déclinons toute responsabilité en la matière.

\section{Copyright}

The University of Lausanne expressly draws the attention of users to the fact that all documents published in the SERVAL Archive are protected by copyright in accordance with federal law on copyright and similar rights (LDA). Accordingly it is indispensable to obtain prior consent from the author and/or publisher before any use of a work or part of a work for purposes other than personal use within the meaning of LDA (art. 19, para. 1 letter a). Failure to do so will expose offenders to the sanctions laid down by this law. We accept no liability in this respect. 
UNIVERSITE DE LAUSANNE - FACULTE DE BIOLOGIE ET DE MEDECINE

Département des services de chirurgie et d'anesthésiologie Service d'anesthésiologie

Helicopter rescue involving the winching of a physician.

\section{THESE}

préparée sous la direction du Docteur Patrick Schoettker

et présentée à la Faculté de biologie et de médecine de I'Université de Lausanne pour l'obtention du grade de

DOCTEUR EN MEDECINE

par

Jocelyn CORNICHE

Médecin diplômé de la Confédération Suisse

Originaire de Genève (GE)

Lausanne

2012 


\section{Helicopter Rescue Involving the Winching of a Physician}

Jocelyn Corniche, MD, ${ }^{1}$ Mathieu Pasquier, MD, ${ }^{2}$ Bertrand Yersin, MD, ${ }^{2}$ Christian Kern, MD, ${ }^{1}$ and Patrick Schoettker, $\mathrm{MD}^{1}$

\begin{abstract}
Introduction: We sought to study the operational and medical aspects of helicopter rescue missions involving the use of a winch. Setting: A single helicopter-based medical service of a pre-alpine region of Switzerland.

Methods: We prospectively studied consecutive primary rescue interventions involving winching of a physician, from October 1, 1998 to October 1, 2002. Demographic, medical and operational aspects as well as outcome at 48 hours were analyzed.

Results: We included 133 patients. Most (74\%) were male, with traumatic injuries (77\%). The median scene time of the nine severely injured patients (Injury Severity Scale [ISS] > 15) was significantly longer compared with the other patients (54 vs 37 minutes; $P<.05)$. The main medical procedures performed were orotracheal intubation ( $n=5)$, fracture reductions $(n=5)$, major analgesia with sedation $(n=4)$, and intravenous fluid administration of more than $1,500 \mathrm{~mL}(\mathrm{n}=4)$. Fourteen $(10 \%)$ patients suffering from minor injuries were triaged by the physician and not airlifted to the hospital. All 133 patients were alive at 48 hours. Sixty-nine (52\%) were still hospitalized. No secondary interhospital transfer was required.
\end{abstract}

Conclusion: Our study provides a better knowledge of injury profile, medical aspects, and outcomes of patients rescued necessitating a winching procedure.

\section{Introduction}

The use of helicopters in prehospital medical systems as well as the type of staffing is under debate., ${ }^{1,2}$ Issues such as cost, effectiveness, safety, and resource allocation are criticized, ${ }^{3,4}$ while dispatch criteria are under review and lack general applicability. ${ }^{5}$ Nevertheless, dispatching of a trained physician in the prehospital setting by means of road or air is common in

\section{Anesthesiology Department, University Hospital Center, Lausanne, Switzerland}

2. Emergency Service, University Hospital Center, Lausanne, Switzerland

Address for correspondence :

Jocelyn Corniche, Anesthesiology Department, University Hospital Center, Rue du Bugnon 21, Lausanne, 1005, Switzerland, Jocelyn.Corniche@chuv.ch

$1067-991 X / \$ 36.00$

Copyright 2012 Air Medical Journal Associates doi:10.1016/j.amj.2011.08.003
European and Australasian health systems ${ }^{6-8}$ and has been shown to improve patient outcome in controlled settings. ${ }^{9,10}$

Mountains cover $60 \%$ of Switzerland. Mountain-related outdoor activities such as climbing, paragliding, and trekking are popular, and accidents are therefore common. This setting implies that access to patients can be difficult or impossible by ordinary means and necessitates the use of a helicopter equipped with a winch when landing is impossible.

Previous studies in the same setting showed that a quarter of the patients rescued with a winch were severely injured. Interval between time of injury and arrival at hospital was greatly increased because of access difficulties. ${ }^{11}$

To assess the pattern and severity of injury and the relevance of medical procedures during hoisting operations, we studied consecutive helicopter rescue operations involving the use of a winch in our Swiss helicopter base.

\section{Setting}

The REGA is a nonprofit organization dedicated to rescue of injured patients. It includes helicopters dispatched to the scene of an accident to triage and care for the injured patients or to provide access in remote areas. Switzerland $\left(41,000 \mathrm{~km}^{2}\right)$ has 17 air medical bases for 7 million inhabitants. The REGA helicopter base of Lausanne, where the study took place, covers a population of 800,000 inhabitants, and is located in a prealpine region. It operates one single helicopter, a Eurocopter EC145, equipped with a winch. The maximum flight time to the site of an accident is 15 minutes. The helicopter crew includes one pilot, one physician with extensive training in anesthesia and emergency medicine, and one flight assistant experienced in rescue procedures. Each physician is trained in helicopter winch rescue procedures, and, in case of difficult terrain, a mountain guide with basic medical knowledge and familiar with helicopter rescue can be called on to assist the physician at the scene. The REGA helicopters are dispatched according to specific keywords such as ejection from a fourwheel vehicle, entrapment, injured or unconscious child, paraor tetraplegia, accidents involving more than three injured patients, limb amputation, and call from a physician or rescue team in a remote area needing air retrieval. In the event a winch is needed, and depending on the type and severity of the injuries, horizontal evacuation can be provided with the help of a specially designed net or air rescue bag (www.rega.ch). Patients with lower or upper arm injuries can be winched with a harness in the seated position. 
Table 1. Characteristics of the Patients

\begin{tabular}{lcc}
\hline & Men & Women \\
\hline Number (\%) & $98(74)$ & $35(26)$ \\
Mean age & 35 & 49 \\
Trauma & 72 & 30 \\
SBP $<$ 90 mmHg & 6 & 3 \\
HR $>100 / \mathrm{min}$ & 18 & 6 \\
GCS 14-15 & 87 & 33 \\
GCS 9-13 & 5 & 2 \\
GCS 3-8 & 5 & 1 \\
\hline
\end{tabular}

SBP, systolic blood pressure; HR, heart rate; GCS, Glasgow Coma Scale.

Standard procedure is for the emergency physician to be the first person to access the patient after analyzing the accident scene and the setting. Situations encountered vary greatly and range from traffic accidents to cardiac emergencies in remote places to people being just lost or exhausted. The physician's role is to evaluate, treat, and prepare the patient for extraction in a timely and safe manner. Once the patient is winched, the physician decides on further treatments, and, usually, advanced medical procedures are performed after the winching procedure and before the flight to hospital. Logistic decisions such as choice of receiving hospital, timeliness of evacuation, and procedures before, during, and after winching are at the discretion of the physician.

\section{Methods}

We prospectively reviewed the medical records of helicopter rescue operations from the Lausanne base of the Swiss Air Rescue Helicopter Service (REGA). The consecutive rescue missions from October 1, 1998 to October 1, 2002 were analyzed. All patients for whom winching of the physician was performed were included. Patients lost to follow-up, those with missing data, or those pronounced dead at the scene without any resuscitation attempt were excluded. Secondary missions (ie, inter-hospital transfer) were also excluded from the analysis.

The demographic data and the vital signs at the scene and during the flight were collected. We used the National Advisory Committee of Aeronautics score to describe the type of terrain where the missions took place. Operational parameters such as response time (from call to patient access) and scene time (time of patient access to takeoff), difficulty of access, and time to hospital (time from takeoff to hospital landing) were extracted from the pilot's log. The severity of the injury was graded using the Abbreviated injury Scale. An Injury Severity Score (ISS) of greater than 15 was used to define severe injury. The following on-scene and in-flight medical main procedures were registered: orotracheal intubation, administration of vasoactive drugs, major analgesia with sedation (ketamine, midazolam, fentanyl, morphine), intravenous fluid administration of more than $1,500 \mathrm{~mL}$, and frac- ture reductions. The hospital final diagnosis, the outcome at 48 hours, and follow-up data were also collected.

Descriptive statistics were expressed as a mean and 95\% confidence interval or median with interquartile range, as appropriate. We explored differences in characteristics between patients using chi-squared tests for categorical variables. We used two-sided $P$-values of $<.05$ to assess statistical significance. Data were analyzed with the Student's unpaired t-test or Mann-Whitney when required. Our institutional review board approved the study.

\section{Results}

One thousand eight hundred fifty-five primary interventions were conducted during the study period. The physician had to be winched in 156 (8.4\%) rescue operations. Fifteen of these patients, who were obviously dead at the scene, and eight that had incomplete files with missing data, were excluded, leaving 133 patients for analysis.

The demographics data of the 133 included patients are shown in Table 1. Most patients were male, with a male: female sex ratio of 2.8: 1. Traumatic lesions were predominant, occuring in $102(77 \%)$ patients. The locations where the events took place are presented in Table 2. Only $1 \%$ of the rescue sites were accessible by car, $50 \%$ by foot only, and $49 \%$ were not accessible at all. The timings of the rescues are shown in Table 3 . The median scene time was significantly longer in the severely injured group in comparison with the other patients ( 54 vs 37 minutes; $P<.05$ ).

The type and severity of injuries are summarized in Table 4. Extremities and pelvis were the most frequently encountered lesions, in 69 (41\%) patients. Thirty (23\%) patients had more than one injured body region. Nine patients were considered severely injured (ISS > 15).

The diagnosis, management, and outcome of the nine severely injured patients is shown in Table 5. Intubation was necessary in four (44\%) patients, but it did not result in an increase of the scene time $(P=.54)$.

Altogether, the main medical procedures performed were orotracheal intubation $(n=5)$, administration of vasoactive drugs $(n=2)$, major analgesia with sedation $(n=4)$, intravenous fluid administration of more than $1,500 \mathrm{~mL}(\mathrm{n}=4)$, and fracture reductions $(n=5)$. Four of the five intubated patients were suffering from severe head trauma and one patient from severe facial trauma.

Fourteen (10\%) patients suffering from minor injuries were triaged by the physician and not airlifted to the hospital. All 133 patients were alive at 48 hours. Sixty-nine (52\%) were still hospitalized, 12 (9\%) in the intensive care unit. No secondary interhospital transfer was required.

\section{Discussion}

Our results demonstrate that most rescues involved young male patients suffering from traumatic lesions. The injury took place in difficult or impossible to access locations. Extremities and pelvis were the most frequently encountered 
Table 2. Location of the Events According to the Modified U.S. National Advisory Committee of Aeronautics Index (NACA-L)

\begin{tabular}{|c|c|c|c|}
\hline NACA-L & Description & $n$ & $\%$ \\
\hline $\mathrm{D}$ & Impossible by car, accessible by foot & 20 & 15 \\
\hline $\mathrm{E}$ & Uneasy access by foot, landing possible & 47 & 35 \\
\hline $\mathrm{F}$ & Landing impossible, simple winch operation & 63 & 47 \\
\hline G & Landing impossible, difficult winch operation & 2 & 2 \\
\hline
\end{tabular}

Table 3. Rescue Times by Severity of the Injury (Minutes, Median, Quartiles)

\begin{tabular}{lccc}
\hline & Moderate (124) & Severe* (9) & Total (133) \\
\hline Response time $^{\dagger}$ & $22(17.25-29.75)$ & $25(18.5-49)$ & $22(17.5-29.5)$ \\
Scene time $^{\ddagger}$ & $37(28-50.75)$ & $54(35.5-59.5)$ & $38(28-52)$ \\
Time to hospital $^{\S}$ & $6.5(4-11)$ & $11(8-15)$ & $7(5-11.5)$ \\
\hline
\end{tabular}

*Defined as ISS $>15$

†Time from call to patient access

$\ddagger$ Time from patient access to takeoff. Scene time was significantly longer in the severely injured group $(P<.05)$

$\S$ Time from takeoff to hospital landing

lesions sites. The scene time was significantly longer for the nine severely injured patients. Advanced medical procedures were performed 20 times. Fourteen (10\%) patients suffering from minor injuries were triaged by the physician and not airlifted to the hospital. All 133 patients were alive at 48 hours, and no secondary interhospital transfer was required.

Outdoor-related activity has been on the rise in recent years around the world, and more individuals are participating in hiking, mountaineering, and climbing for its extreme nature. ${ }^{12,13}$ Furthermore, hiking and backpacking are among those activities with the largest growth in participation, and this increase has resulted in many different experience levels. ${ }^{14}$ An inherent degree of risk is associated with these activities that can result in negative health experiences, leading to search-and-rescue operations that can have a significant impact on local medical resources. Search and rescue refers to an operation commenced by emergency services to find individuals believed to be in distress, ill or injured, and possibly lost in remote areas or areas that are difficult to access.

The studied helicopter base is located in a pre-alpine region, and missions range from accidents on highways to rescue in difficult terrain, necessitating the use of a winch in $8.4 \%$ of primary mission. In the same helicopter base, Moeschler et $\mathrm{al}^{11}$ found a higher rate of winching operations more than 10 years ago. Demartines et $\mathrm{al}^{15}$ found a rate of $23 \%$ of winching operation in a Swiss mountain base for the same time frame, and Malacrida et $\mathrm{al}^{16}$ published rates up to $30 \%$ of rescue winching. The increase in safety procedures and enhancement of winching guidelines are probably responsible for this decrease in frequency over the years, whereas the absolute numbers of difficult accesses increases.

Comparison with practice in other systems around the world is difficult, because there are very few similar studies to
Table 4. Type and Severity of the Injuries

\begin{tabular}{lccc}
\hline & $\mathbf{n ~ ( \% )}$ & AIS.2 & $\%$ \\
\hline Head \& neck & $23(14)$ & 8 & 20 \\
Face & $14(8)$ & 1 & 3 \\
Chest & $21(12)$ & 8 & 20 \\
Abdomen & $20(12)$ & 4 & 10 \\
Extremity/pelvis & $69(41)$ & 19 & 47 \\
External & $22(13)$ & 0 & 0 \\
\hline Total & $\mathbf{1 6 9}$ & $\mathbf{4 0}$ & \\
\hline
\end{tabular}

be found or because winching capabilities are not available. An Australian study conducted by Flabouris ${ }^{17}$ between 1990 and 2001 found $21 \%$ of patients necessitating the use of the winch, but no recent reassessment of practice has been undertaken.

Fifty-three minutes, the average scene time for severely wounded patients, could be judged as being long. This time, however, includes preparation of the patients for evacuation in the supine position, as opposed to lightly injured patients, who can be evacuated with a harness, and this preparation is time consuming. Safety procedures, a main concern during winching operations, also take time. They include identifying potential dangers when arriving on the site with the helicopter, finding a secondary landing site, holding a short mission briefing before the rescue, and working radio contact between the crew and the emergency physician.

Helicopter emergency medical services are staffed differently throughout the world. In Europe, an emergency physician is dispatched on the accident site, bringing therefore an increased skill set to allow more definitive management of 
Table 5. Characteristic of the Nine Severely Injured Patients

\begin{tabular}{|c|c|c|c|c|c|}
\hline & Scene Time (min) & Intubation & ISS & Diagnosis & Surgery \\
\hline 1 & 46 & No & 19 & Fractured lumbar spine, both ankles and scalp injury & Within 4 hours \\
\hline 2 & 54 & Yes & 36 & Severe TBI, pulmonary and myocardial contusions & Within 4 hours \\
\hline 3 & 26 & No & 16 & Fractured thoracic spine, pulmonary contusion & Within 12 hours \\
\hline 4 & 45 & Yes & 22 & $\begin{array}{l}\text { Hypothermia, moderate brain injury, } \\
\text { burn } 15 \% \text { BSA, fractured clavicle }\end{array}$ & no \\
\hline 5 & 59 & Yes & 18 & Severe TBI, pulmonary contusion & no \\
\hline 6 & 56 & No & 17 & Open book pelvis fracture, femur fracture, scalp injury & Within 4 hours \\
\hline 7 & 60 & Yes & 48 & Severe TBI, facial fracture Lefort III, pulmonary contusion & no \\
\hline 8 & 3 & No & 16 & Fractured lumbar spine, both ankles and scalp injury & no \\
\hline 9 & 332 & No & 24 & $\begin{array}{l}\text { Fractured thoracic and cervical spine with } \\
\text { paraplegia, fractured clavicle }\end{array}$ & Within 10 hours \\
\hline
\end{tabular}

TBI, traumatic brain injury; BSA, body surface area.

All patients were alive and hospitalized in the ICU at 48 hours, except patient 1, who was transferred in the ward.

patients at an earlier stage or to decide the most appropriate facility for the patients' subsequent treatments. In our study, the physician in charge initiated 20 on-site advanced procedures, the most frequent being reduction of fractures, intubation, and major analgesia. In the Swiss prehospital setting, these procedures are performed only by physicians. Paramedics are not involved in our system, and ambulance officers are only taught basic life support skills.

Studies conducted in similar settings but different countries showed that reduction of fractures and splinting belong to the most frequently necessary treatments in remote areas. ${ }^{18,19}$ Reports about prehospital intubation in the wilderness setting or during winching procedures are sparse. There is, however, growing evidence that helicopter use, along with advanced medicalization, could improve the outcome of trauma. ${ }^{5,20,21}$

Moeschler et $\mathrm{al}^{11}$ analyzed retrospectively in the same helicopter base 100 consecutive operations at sites where landing was impossible. They showed that $22 \%$ of patients rescued by winch were severely injured. Their conclusions were that, because the rescue actions were particularly long and difficult, the performance of advanced medical procedures at the scene and during transport were of great value. Those maneuvers give the patient earlier access to pain relief and allow for potentially life-saving airway management.

Prehospital triage was performed by the winched physician and avoided hospitalization for 14 patients, with no secondary need for medical consult. This specific role of the emergency physician in triaging and dispatching of the patient to the most appropriate location must not be underestimated. Of the remaining hospitalized patients, no secondary interhospital transfer was necessary, confirming recent findings of the accuracy of prehospital triage by physician ${ }^{22}$ in the same setting and for the same time frame. Physicians working for the REGA have a good knowledge of the locations and available facilities of the surrounding hospitals. Depending on the type of injuries they suspect, they choose the nearest hospital with facilities and specialty personnel that are able to take care of the patient. Orienting every wounded patient to the main trauma center would have a negative effect, because this would overload the center quickly with minor cases that could be easily treated in smaller hospitals.

The national variations between different air rescue organizations account for the main limitation of our study. Although we believe that our results support the presence of the emergency physician in our specific setting, this may be questionable in other settings or countries, where the training of the paramedical crew, the type of injuries, and the geographical characteristics may be be different.

Winch operations are often the fastest way to access and rescue wounded patients in difficult terrain. Our study provides a better knowledge of the demographic characteristics, injury profile, and outcomes of patients rescued using a winching procedure. The presence of an emergency physician during these specific types of rescue missions allows for advanced medical care when necessary, along with triaging and dispatching the patient directly to the appropriate hospital for definitive care. Further similar studies are needed to allow international comparison of the different helicopterbased emergency services practicing winching procedures.

\section{References}

1. Greene J. Rising helicopter crash deaths spur debate over proper use of air transport. YMEM 2009; 53:A15-7.

2. Frazer E. The National Transportation Safety Board's helicopter emergency medical services public hearings February 3-6, 2009. Air Med J 2009;28:128-9.

3. Talving P, Teixeira PGR, Barmparas G, DuBose J, Inaba K, Lam L, et al. Helicopter evacuation of trauma victims in Los Angeles: does it improve survival? World J Surg 2009;33:2469-76.

4. Ringburg AN, Spanjersberg WR, Frankema SPG, Steyerberg EW, Patka P, Schipper IB. Helicopter emergency medical services (HEMS): impact on on-scene times. J Trauma 2007;63:258-62.

5. Ringburg AN, Thomas SH, Steyerberg EW, van Lieshout EMM, Patka P, Schipper IB. Lives saved by helicopter emergency medical services: an overview of literature. Air Med J 2009;28:298-302. 
6. Ummenhofer W, Scheidegger D: Role of the physician in prehospital management of trauma: European perspective. Curr Opin Crit Care 2002;8:559-65.

7. Garner AA. The role of physician staffing of helicopter emergency medical services in prehospital trauma response. Emerg Med Australas 2004;16:318-23.

8. Schoettker P, Ravussin P. Ejection as a key word for the dispatch of a physician staffed helicopter: the Swiss experience. Resuscitation 2001;49:169-73.

9. Thomas SH, Biddinger PD. Helicopter trauma transport: an overview of recent outcomes and triage literature. Curr Opin Anaesthesiol 2003;16:153-8.

10. Baxt WG, Moody P.The impact of a physician as part of the aeromedical prehospital team in patients with blunt trauma. JAMA 1987;257:3246-50.

11. Moeschler O, Refondini S, Höfliger C, Freeman J. Difficult aeromedical rescue situations: experience of a Swiss pre-alpine helicopter base. J Trauma 1992;33:754-9.

12. Sholl JM, Curcio EP. An introduction to wilderness medicine. Emerg Med Clin North Am 2004;22:265-79, vii.

13. Ariza L, Gomide M, Ramos AN, Leggat PA, Heukelbach J. Survey of visitors to a National Park in the savannah region of northeast Brazil: practices, incidents and hazardous situations. Travel Med Infect Dis 2007;5:1-6.

14. Boulware DR, Forgey WW, Martin WJ. Medical risks of wilderness hiking. Am J Med 2003;114:288-93.

15. Demartines N, Meyer C, Scheidegger D, Harder F. [Helicopter and emergency physician at the accident site. Medical comparison between altitude and flat land emergency care]. Helv Chir Acta 1991;58:223-7.
16. Malacrida RL, Anselmi LC, Genoni M, Bogen M, Suter PM. Helicopter mountain rescue of patients with head injury and/or multiple injuries in southern Switzerland 19801990. Injury 1993;24:451-3.

17. Flabouris A. A description of events associated with scene response by helicopter based medical retrieval teams. Injury 2003;34:847-52.

18. Johnson RM, Huettl B, Kocsis V, Chan SB, Kordick MF. Injuries sustained at Yellowstone National Park requiring emergency medical system activation. Wilderness \& Environmental Medicine 2007;18:186-9.

19. Heggie TW. Search and rescue in Alaska's National Parks. Travel Med Infect Dis 2008;6:355-61.

20. Brown JB, Stassen NA, Bankey PE, Sangosanya AT, Cheng JD, Gestring ML. Helicopters and the civilian trauma system: national utilization patterns demonstrate improved outcomes after traumatic injury. J Trauma 2010;69:1030-4; discussion 1034-6.

21. Ryynänen $O$, lirola T, Reitala J, Pälve $H$, Malmivaara A. Is advanced life support better than basic life support in prehospital care? A systematic review. Scand J Trauma Resusc Emerg Med 2010;18:62.

22. Carron P, Taffe P, Ribordy V, Schoettker P, Fishman D, Yersin B. Accuracy of prehospital triage of trauma patients by emergency physicians: a retrospective study in western Switzerland. Eur J Emerg Med 2011;18:86-93. 